Arq. Bras. Med. Vet. Zootec., v.69, n.4, p.962-972, 2017

\title{
Excesso de tiroxina materna associado ao hipertireoidismo pós-natal reduz o crescimento ósseo e o perfil proliferativo e angiogênico das cartilagens de crescimento de ratos
}

\author{
[Excess maternal thyroxine associated with postnatal hyperthyroidism reduces bone growth \\ and proliferative and angiogenic profile of rats growth cartilage] \\ L.G.R. Ribeiro $^{1}$, J.F. Silva ${ }^{2}$, N.M. Ocarino ${ }^{1}$, E.G. Melo $^{1}$, R. Serakides ${ }^{1 *}$ \\ ${ }^{1}$ Escola de Veterinária - Universidade Federal de Minas Gerais - Belo Horizonte, MG \\ ${ }^{2}$ Instituto de Ciências Biológicas - Universidade Federal de Minas Gerais - Belo Horizonte, MG
}

\begin{abstract}
RESUMO
Foram estudados os efeitos do excesso da tiroxina materna associado ao hipertireoidismo pós-natal sobre o crescimento ósseo e o perfil proliferativo e angiogênico das cartilagens. Dezesseis ratas Wistar adultas foram distribuídas nos grupos tratados com L-tiroxina e controle. A prole do grupo tratado recebeu L-tiroxina do desmame até 40 dias de idade. Ao desmame, foi realizada dosagem plasmática de $\mathrm{T}_{4}$ livre nas mães. Na prole, foram realizados: dosagem plasmática de $\mathrm{T}_{3}$ total e $\mathrm{T}_{4}$ livre, morfometria das tireoides, mensuração do comprimento e largura do fêmur. Nas cartilagens, foi avaliada a expressão imuno-histoquímica e gênica de CDC-47, VEGF, Flk-1, Ang1, Ang2 e Tie2. As médias entre grupos foram comparadas pelo teste $\mathrm{T}$ de Student. As concentrações de T4 livre das mães tratadas e de $\mathrm{T}_{3}$ total e $\mathrm{T}_{4}$ livre da prole foram significativamente mais elevadas. A largura do fêmur foi menor nos animais tratados. Houve também redução da imunoexpressão de CDC-47 e de VEGF e dos transcritos gênicos para VEGF e Ang1 nas cartilagens. Conclui-se que o excesso de tiroxina materna associado ao hipertireoidismo pós-natal reduz a largura da diáfise femoral, a proliferação celular e a expressão de VEGF e de Ang1 nas cartilagens de crescimento de ratos.
\end{abstract}

Palavras-chave: rato, tiroxina, hipertireoidismo congênito, cartilagem de crescimento, angiogênese

\begin{abstract}
The effects of excess of maternal thyroxine associated with postnatal hyperthyroidism at bone growth and proliferative and angiogenic profile of cartilage were studied. Sixteen adult Wistar rats were divided into treated and control groups. The offspring of the treated group received L-thyroxine from weaning to 40 days-old. At weaning, plasma assay of free $T_{4}$ was measurement on female rats. In the offspring, the following assessments were performed: measurement of total $T_{3}$ and free $T_{4}$, histomorphometry analysis of the thyroid, measurement of body weight and length and width of the femur. In femoral growth cartilage, immunostaining of CDC-47, gene or protein expression of VEGF, Flk-1, Ang1, Ang2 and Tie 2 were evaluated. Data were analyzed using Student's $t$-test. Free $T_{4}$ was significantly higher in treated rats and total $T_{3}$ and free $T_{4}$ were significantly higher in offspring. The width of the femur was significantly lower in treated animals. There was lower immunoreactivity of CDC-47, VEGF and lower expression of gene transcripts for VEGF and Ang1. We concluded that the excess maternal thyroxine associated with postnatal hyperthyroidism reduces the width of the femoral shaft, the cell proliferation and gene and protein expression of VEGF and gene expression of Angl on the growth cartilage in rats.
\end{abstract}

Keywords: rat, thyroxine, congenital hyperthyroidism, growth cartilage, angiogenesis

Recebido em 7 de julho de 2016

Aceito em 8 de setembro de 2016

* Autor para correspondência (corresponding author)

E-mail: serakidesufmg@gmail.com 


\section{INTRODUÇÃO}

Os hormônios tireoidianos maternos têm ação crítica em todos os sistemas da prole durante a gestação e a lactação (Mestman, 2004; Medici et al., 2013). O hipertireoidismo materno pode estar associado ao hipertireoidismo transitório fetal e neonatal (Polak et al., 2006). O hipertireoidismo congênito, se não reconhecido e tratado, pode ter efeitos graves sobre o crescimento ósseo, particularmente nos primeiros dois anos de vida (Segni e Gorman, 2001). A tireotoxicose juvenil pode estar associada ao crescimento acelerado e à idade óssea avançada. No entanto, há relatos de redução da estatura devido à fusão prematura das placas de crescimento (Segni et al., 1999; Bassett et al., 2007).

A formação e o crescimento ósseos são controlados principalmente pelas taxas de proliferação, pela síntese de matriz extracelular e pela hipertrofia dos condrócitos da placa epifisária (Hunziker, 1994; Ballock e O'Keefe, 2003). As células que participam do processo, como os condroblastos, os osteoblastos e os osteoclastos, devem apresentar interação funcional com o sistema vascular, sendo, inclusive, reguladas por moléculas pró e antiangiogênicas (Carrington e Reddi, 1991; Maes, 2013). O VEGF é o principal regulador da angiogênese, durante os desenvolvimentos embrionário, fetal e pós-natal, e da sobrevivência e atividade das células das linhagens condrogênica e osteoblástica (Ferrara et al., 2003). Além do VEGF, as angiopoetinas (Ang) e seus receptores tirosina quinase (Tie2) também são importantes para angiogênese, e, em humanos, já foram identificadas em locais de ossificação endocondral em coexpressão com VEGF (Horner et al., 2001).

Apesar de os hormônios, os fatores de crescimento, os genes e as vias de sinalização que controlam o crescimento ósseo serem amplamente estudados, o mecanismo pelo qual ocorre redução do crescimento ósseo induzido pelo excesso de tiroxina materna associado ao hipertireoidismo pós-natal permanece desconhecido. Assim, o objetivo do presente estudo foi avaliar os efeitos do excesso de tiroxina materna associado ao hipertireoidismo pós-natal nas cartilagens de crescimento da prole, por meio da avaliação do perfil proliferativo, baseado na expressão de CDC-47, e do perfil angiogênico, pela expressão imunohistoquímica e/ou de transcritos gênicos para VEGF, Flk-1, Ang1, Ang2 e Tie2.

\section{MATERIAL E MÉTODOS}

Todos os procedimentos foram aprovados pelo Comitê de Ética em Experimentação Animal da UFMG (Protocolo $n^{\circ}$. 47/2014).

Foram utilizadas 16 ratas Wistar, com dois meses de idade, as quais foram acasaladas com ratos adultos, e a cópula foi confirmada pela presença de espermatozoides na citologia vaginal (Silva $e t$ al., 2013). No primeiro dia de gestação, as ratas foram distribuídas em dois grupos distintos, cada um com oito animais. O grupo tratado recebeu diariamente L-tiroxina (Sigma-Aldrich, St. Louis, MO, USA), via oral, na dose de 50 $\mu$ g/animal, diluída em $5 \mathrm{~mL}$ de água destilada, de acordo com protocolos previamente estabelecidos (Silva et al., 2013), por todo período da gestação e da lactação. Nas fêmeas do grupo controle, foram fornecidos como placebo $5 \mathrm{~mL}$ de água destilada durante todo o período experimental.

De cada rata dos grupos controle e tratado com L-tiroxina, foi separado um filhote no desmame, ou seja, aos 20 dias de idade. Os filhotes das ratas do grupo tratado receberam $50 \mu \mathrm{g} / \mathrm{animal} /$ dia L-tiroxina diluída em $1 \mathrm{~mL}$ de água destilada. Assim, esses animais foram submetidos ao excesso de tiroxina materna durante a gestação e a lactação e, após o desmame, continuaram recebendo tiroxina por mais 20 dias. Os filhotes do grupo controle receberam $1 \mathrm{~mL}$ de água destilada como placebo. Dessa forma, foram constituídos dois grupos: 1) filhos hipertireoideos de ratas tratadas com Ltiroxina $(n=8)$ e 2) filhos eutireoideos de ratas controle. A eutanásia foi realizada por punção cardíaca precedida por anestesia com xilazina $(40 \mathrm{mg} / \mathrm{kg} / \mathrm{IP}$; Vetnil, Brasil) e quetamina (10mg/kg/IP; Konig, Brasil).

O plasma das ratas aos 20 dias de lactação e da prole aos 40 dias foi armazenado a $-20^{\circ} \mathrm{C}$ para dosagem de T4 livre nas mães e de T3 total e T4 livre na prole pela técnica de ELISA de quimioluminescência (Serakides et al., 2008).

Para a avaliação morfométrica, as tireoides da prole foram fixadas em formalina $10 \%$ neutra e tamponada e processadas de acordo com a 
técnica rotineira de inclusão em parafina, com secções histológicas de $4 \mu \mathrm{m}$, coradas por HE. Foram mensurados, ao acaso e com auxílio de uma ocular micrométrica com régua, os diâmetros maior e menor de 30 folículos, obtendo-se a média dessas medidas em cada tireoide. A altura do epitélio foi mensurada em quatro pontos distintos e equidistantes em 20 folículos, obtendo-se o valor médio. Essa mensuração foi realizada com auxílio de uma ocular micrométrica com régua acoplada ao microscópio, em objetiva de 100x (Serakides et al., 2000).

Aos 40 dias de idade dos grupos hipertireoideo e controle, foram obtidas as médias do peso corporal individual $(\mathrm{g})$, do comprimento do fêmur direito, medido da epífise proximal até a epífise distal, e da largura, medida no meio da diáfise do osso.

Os fêmures direitos dos animais de cada grupo experimental foram fixados em formalina $10 \%$ neutra e tamponada por, no máximo, 48 horas e submetidos à descalcificação, pela utilização de solução ácida de EDTA por 24h. Posteriormente, os ossos foram colocados na segunda solução de EDTA a 10\%, em água destilada, até completa descalcificação (Pitol et al., 2007). Em seguida, os ossos foram processados pela técnica rotineira de inclusão em parafina e submetidos à microtomia para obtenção de secções histológicas de $4 \mu \mathrm{m}$, coradas por HE. A porcentagem de tecido ósseo trabecular foi determinada tanto na epífise quanto na metáfise distal do fêmur em três campos, em objetiva de 20x, com auxílio de uma gratícula com 121 pontos acoplada à ocular do microscópio óptico. A espessura das trabéculas foi determinada com base na média tomada de três pontos equidistantes por trabécula, em um total de 20 trabéculas ósseas da região metafisária, abaixo da placa epifisária, em objetiva de 10x. As espessuras das cartilagens articulares e das placas epifisárias e das suas zonas foram determinadas pela média das espessuras em 15 pontos equidistantes, em objetiva de 10x. Essas avaliações foram realizadas com o auxílio de uma ocular com régua.

As secções histológicas da epífise e da metáfise distais dos fêmures foram submetidas à imunohistoquímica para atividade proliferativa com o anticorpo anti-CDC-47 (47DC14; Neomarkers,
Fremont, CA, USA, diluição 1:50) e perfil angiogênico com o uso do anticorpo anti-VEGF (sc-152; Santa Cruz, CA, USA, diluição 1:50). Foi utilizada a técnica da estreptavidina-biotinaperoxidase (Streptavidin Peroxidase, Dako, St Louis, MO, USA) e recuperação antigênica pelo calor em banho-maria a $98^{\circ} \mathrm{C}$ com solução de Trilogy ${ }^{\circledR}$. As secções histológicas foram incubadas em câmara úmida overnight, com o anticorpo primário, e por 30 minutos em cada uma das etapas seguintes, bloqueio da peroxidase endógena, soro de bloqueio (Dako, St Louis, MO, USA) e estreptavidina peroxidase. O anticorpo secundário foi incubado por $45 \mathrm{~min}$ (Dako, St Louis, MO, USA). O cromógeno foi a diaminobenzidina (Dako, St Louis, MO, USA). As secções foram contracoradas com methyl green para o CDC-47 e com hematoxilina de Harris para o VEGF. O controle negativo foi obtido pela substituição do anticorpo primário por soro bloqueio e como controle positivo, foram utilizadas secções histológicas de baço de rato.

As análises imuno-histoquímicas foram realizadas em toda a extensão das cartilagens de crescimento do fêmur dos grupos tratado e controle e isoladamente na zona hipertrófica. As células imunomarcadas foram avaliadas em 10 campos/secção histológica em objetiva de 40x, por meio de imagens capturadas pelo microscópio Leica DM 4000B com câmera digital acoplada. A porcentagem de células CDC-47 positivas foi determinada considerandose o número total de células por campo, usandose o software ImagePro-plus (Media Cybernetics Manufacturing, Rockville, MD, USA). Para o anti-VEGF, determinou-se a área e a intensidade de imunomarcação em pixels usando-se o software WCIF Image $\mathrm{J} \circledast$ (Media Cybernetics Manufacturing, Rockville, MD, USA). A avaliação foi realizada tanto na cartilagem articular quanto na placa epifisária do fêmur. Cada um dos fatores foi avaliado nas zonas superficial, média e profunda da cartilagem articular e também nas zonas de repouso, proliferativa e hipertrófica da placa epifisária.

A quantificação relativa da expressão de Vegf (F:GCCCAGACGGGGTGGAGAGT; R: AGGGTTGGCCAGGCTGGGAA), Flk-1 (F:GTCCGCCGACACTGCTGCAA; R: CTCGCGCTGGCACAGATGCT), Angl 
(F:GTCAGCCTTTGCACAAAAGAAGTTT; R:TCCAGCCCCTCTGGAAATCT), Ang2 (F:TGCCTGCAAGTTTGCTGAAC; R:GGCTGAGGCCAAGACAAGAT) e Tie2 (F:CGGCTTAGTTCTCTGTGGAGTC; R: GGCATCAGACACAAGAGGTAGG) foi realizada pela técnica de RT-PCR, em tempo real, em fragmentos da cartilagem articular do fêmur esquerdo dos ratos hipertireoideos e controle. Essas cartilagens foram coletadas em trizol (Invitrogen, Carlsbad, CA, USA), congeladas em nitrogênio líquido por duas horas e armazenadas a $-80^{\circ} \mathrm{C}$. A concentração de RNA de cada grupo foi determinada pela leitura da absorbância por espectrofotometria a 260/280nm. Para as reações de transcrição reversa, foi utilizado kit comercial SuperScript ${ }^{\circledR}$ III First-Strand SynthesisSuper Mix qRT-PCR (Invitrogen, Carlsbad, CA, USA), sendo utilizados $10 \mu \mathrm{L}$ de $2 x$ RT reaction MIX, $2 \mu \mathrm{L}$ de RT enzyme MIX, $6 \mu \mathrm{L}$ de água DEPC e $2 \mu \mathrm{L}$ de RNA contendo $0,5 \mu \mathrm{g}$ de $\mathrm{RNA} / \mu \mathrm{L}$ para um volume final de $20 \mu \mathrm{L}$. A transcrição reversa foi realizada em um termociclador, com a programação de $25^{\circ} \mathrm{C}$ por 10 minutos, $42^{\circ} \mathrm{C}$ por 50 minutos e $85^{\circ} \mathrm{C}$ por cinco minutos. Posteriormente, foi adicionado $1 \mu \mathrm{L}$ de RNase $\mathrm{H}$ por microtubo e novamente colocado no termociclador por 20 minutos a $37^{\circ} \mathrm{C}$. Para as reações de PCR em tempo real, foram utilizados $2,5 \mu \mathrm{L}$ de cDNA, $1,0 \mu \mathrm{L}$ de cada iniciador, $1,0 \mu \mathrm{L}$ de ROX, $7 \mu \mathrm{L}$ de água DEPC livre de RNAse e $12,5 \mu \mathrm{L}$ do reagente SYBR Green, em um volume final de $25 \mu \mathrm{L}$ de reação no aparelho 7500 Real-Time PCR System. Os parâmetros utilizados para amplificação foram: $50^{\circ} \mathrm{C}$ por 120 segundos, $95^{\circ} \mathrm{C}$ por 150 segundos e 45 ciclos de $95^{\circ} \mathrm{C}$ por 15 segundos e $60^{\circ} \mathrm{C}$ por 30 segundos. Os iniciadores foram delineados com base na sequência do mRNA Rattus norvegicus. A expressão gênica foi calculada usando-se o método $2^{-\Delta \Delta \mathrm{CT}}$, e os resultados obtidos foram comparados quantitativamente após a normalização baseada na expressão de betaactina (Actina- $\beta$ ) Rattus norvegicus.

O delineamento foi inteiramente ao acaso e, para cada variável, foram determinados a média e o desvio-padrão. Foi realizada a comparação das médias pelo teste $\mathrm{t}$ de Student, pelo pacote computacional GraphPad Prism 6. Diferenças foram consideradas significativas se $\mathrm{P}<0,05$ (Sampaio, 2002).

\section{RESULTADOS}

O tratamento com tiroxina aumentou a concentração plasmática de $\mathrm{T}_{4}$ livre nas ratas com 20 dias de lactação quando comparadas com as ratas do grupo controle $(\mathrm{P}<0,05)$. Na prole com 40 dias, o hipertireoidismo foi confirmado nos animais tratados pelo aumento significativo da concentração plasmática de $\mathrm{T}_{3}$ total e $\mathrm{T}_{4}$ livre, comparados com o grupo controle (Fig. 1A). Além disso, todos os animais tratados com Ltiroxina exibiram sinais clínicos caracterizados por hiperatividade e agressividade.

As tireoides, independentemente do grupo experimental, apresentaram folículos redondos a ovais e com diâmetros variados. No grupo controle, os folículos eram revestidos por epitélio predominantemente cuboidal e preenchidos por coloide denso e, por vezes, vacuolizado, enquanto nos ratos hipertireoideos, foi observada predominância de folículos com diâmetro grande e uniforme e revestidos por epitélio achatado. A morfometria confirmou a diferença entre grupos. Foi observado, no grupo hipertireoideo, aumento significativo do diâmetro dos folículos e redução significativa da altura do epitélio folicular em comparação aos do grupo controle (Fig. 1B-D).

Não foram observadas diferenças significativas no peso corporal e no comprimento do fêmur entre grupos. No entanto, a largura do fêmur foi significativamente menor nos animais hipertireoideos (Tab. 1).

Em ambos os grupos, a placa epifisária apresentava espessura compatível com a idade dos animais. Entretanto, em alguns animais do grupo tratado, foi observada desorganização das zonas da placa epifisária. No grupo hipertireoideo não foi observada diferença significativa na espessura total da placa epifisária e das zonas de repouso e hipertrófica em relação ao controle. No entanto, a espessura da zona proliferativa foi significativamente menor comparada à do grupo controle (Fig. 2A e E). Já a espessura da cartilagem articular e de todas as suas zonas foi significativamente menor no grupo hipertireoideo comparada à do controle (Fig. 2B e E). 

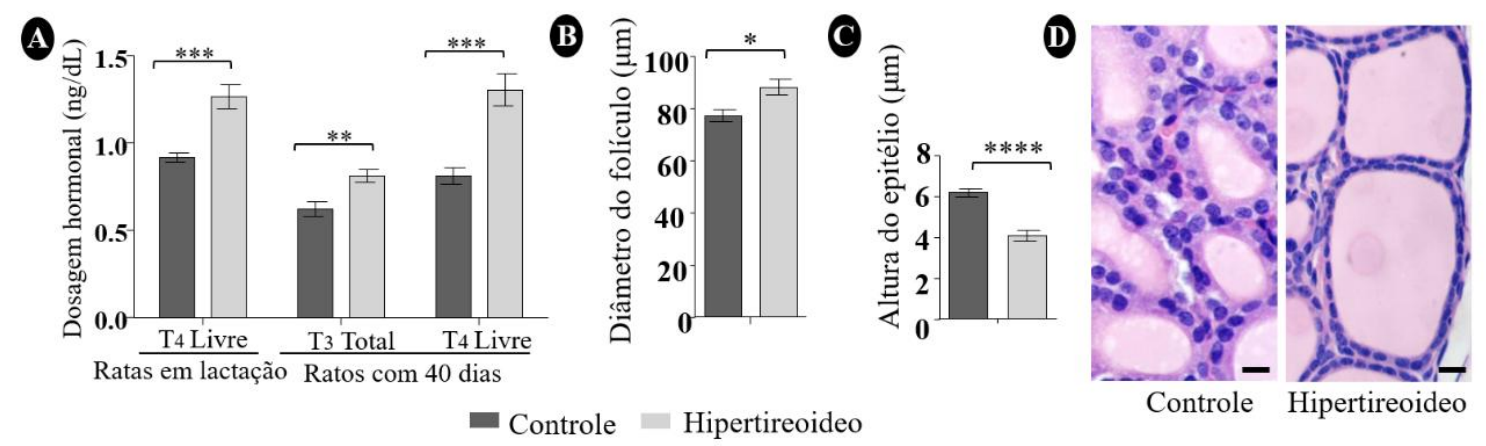

Figura 1. Níveis de hormônios da tireoide (média \pm SD) no plasma das ratas em lactação e da prole dos grupos controle e tratado com L-tiroxina e histomorfometria da tireoide. A) Aumento nas concentrações plasmáticas de $\mathrm{T}_{4}$ livre $(\mathrm{P}<0.001)$ nas ratas tratadas e aumento de $\mathrm{T}_{3}$ total $(\mathrm{P}<0,01)$ e de $\mathrm{T}_{4}$ livre $(\mathrm{P}<0.001)$ no grupo hipertireoideo. B) Aumento no diâmetro folicular $(\mu \mathrm{m})$ no grupo hipertireoideo $(\mathrm{P}>0,05)$. C) Redução da altura do epitélio folicular $(\mu \mathrm{m})$ da tireoide no grupo hipertireoideo $(\mathrm{P}<0,0001)$. D) Fotomicroscopia da tireoide com alterações descritas nos gráficos. HE, barra:18,5 $\mu \mathrm{m}$.

Tabela 1. Média, desvio-padrão e valor de $\mathrm{P}$ das variáveis analisadas na prole de 40 dias de idade, controle e tratadas com L-tiroxina

\begin{tabular}{lccc}
\hline Variáveis & Grupo controle & Grupo tratado & Valor de P \\
\hline Peso corporal $(\mathrm{g})$ & $150,0 \pm 4,145$ & $140,2 \pm 3,523$ & $0,0932 \mathrm{NS}$ \\
Comprimento do fêmur $(\mathrm{mm})$ & $2,577 \pm 0,01257$ & $2,565 \pm 0,02469$ & $0,6588 \mathrm{NS}$ \\
Largura do fêmur $(\mathrm{mm})$ & $3,125 \pm 0,08768$ & $2,729 \pm 0,04384$ & $0,0012^{* *}$ \\
\hline
\end{tabular}

Nos grupos controle e hipertireoideo, o tecido ósseo trabecular apresentava características semelhantes. As trabéculas epifisárias e metafisárias do fêmur eram numerosas, espessas e confluentes. Os osteoblastos recobriam toda a superfície das trabéculas e apresentavam-se ora cuboidais e com núcleo volumoso e oval, ora achatados com núcleo fusiforme e intensamente basofílico. Os osteócitos apresentavam-se, por vezes, com núcleos pequenos alojados em lacunas estreitas e pouco basofílicas ou com núcleos volumosos alojados em lacunas largas com bordas basofílicas. Confirmando a análise morfológica, não foi observada diferença entre grupos com relação à espessura das trabéculas ósseas e à porcentagem de tecido ósseo trabecular na epífise e na metáfise do fêmur (Fig. 2C, D e E).

Nos dois grupos, a taxa de proliferação, caracterizada pela expressão de CDC-47, foi representada pela marcação positiva nuclear, principalmente nas zonas proliferativa e média, em menor quantidade nas zonas de repouso e rara nas zonas hipertróficas da placa epifisária, com padrão similar nas zonas da cartilagem articular. Nos ratos hipertireoideos, a imunoexpressão do CDC-47 foi significativamente menor nos condrócitos da cartilagem articular e da placa epifisária dos fêmures em comparação ao controle (Fig. 3).

A expressão imuno-histoquímica de VEGF revelou imunomarcação citoplasmática e nuclear em todas as zonas das cartilagens de crescimento em ambos os grupos. Contudo, nos ratos hipertireoideos, houve significativa redução na área e na intensidade de imunomarcação em toda a placa epifisária e na cartilagem articular, especificamente na zona hipertrófica da placa epifisária, em comparação ao controle (Fig. 4).

Os ratos hipertireoideos apresentaram redução significativa da expressão gênica para Vegf e Angl e ausência de diferença significativa na expressão dos demais transcritos (Fig. 5). 

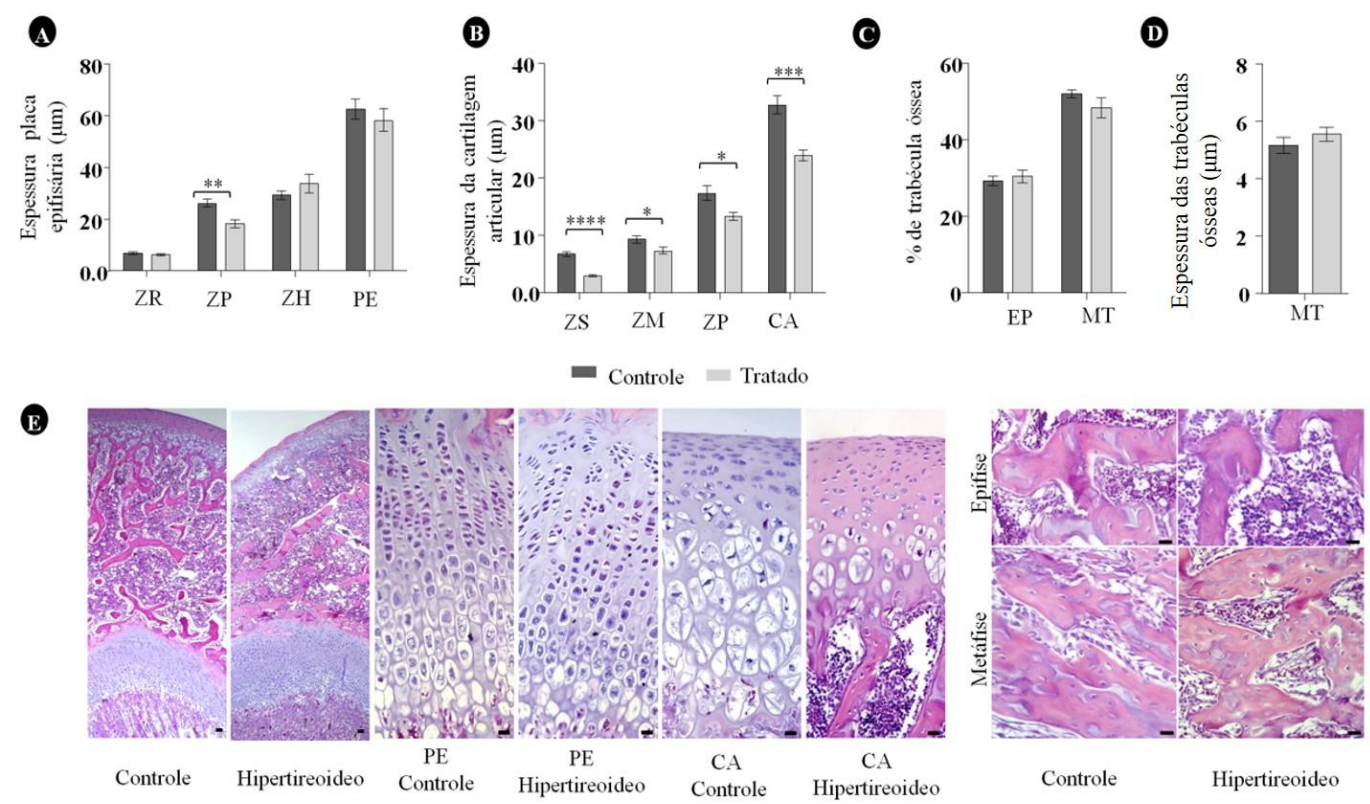

Figura 2. Histomorfometria óssea da região distal dos fêmures de ratos controle e hipertireoideo. A) Espessura da placa epifisária e suas zonas, com redução da zona proliferativa da $\mathrm{PE}$ dos ratos hipertireoideos em comparação ao controle $(\mathrm{P}<0,01)$. B) Redução da espessura da cartilagem articular $(\mathrm{P}<0,001)$ e suas zonas superficial $(\mathrm{P}<0,0001)$, média $(\mathrm{P}>0,05)$ e profunda $(\mathrm{P}>0,05)$ nos ratos hipertireoideos em comparação ao controle. C) Porcentagem de trabéculas ósseas metafisárias e epifisárias $(P>0,05)$. C) Porcentagem de trabéculas ósseas metafisárias e epifisárias $(P>0,05)$. D) Espessura das trabéculas ósseas metafisárias $(\mathrm{P}>0,05)$. E) Fotomicroscopia da epífise e da $\mathrm{PE}$ demonstrando desorganização e redução da espessura da zona proliferativa e as alterações evidenciadas nos gráficos. HE, barra:18,5 $\mu \mathrm{m}$. CA: cartilagem articular; EP: epífise; PE: placa epifisária; MT: metáfise; ZR: zona de repouso; ZP: zona proliferativa; ZH: zona hipertrófica; ZS: zona superficial; ZM: zona média; ZP: zona profunda.
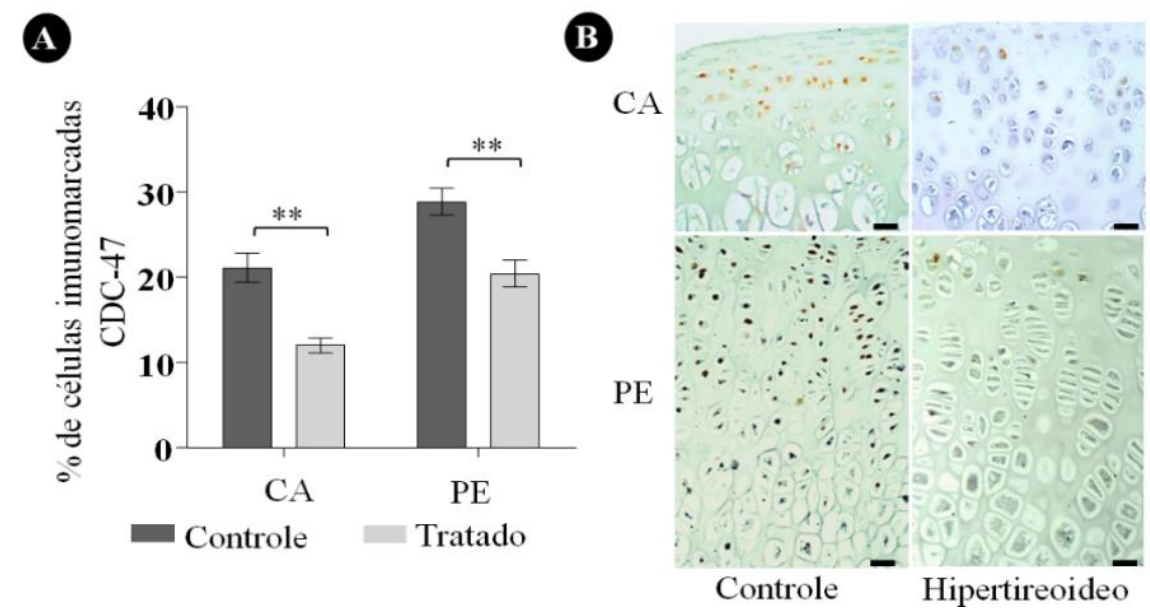

Figura 3. Expressão imuno-histoquímica de CDC-47 nas cartilagens de crescimento dos fêmures de ratos controle e hipertireoideo. A) Redução da porcentagem de células imunomarcadas na $\mathrm{CA}(\mathrm{P}<0,001)$ e na PE $(\mathrm{P}<0,001)$. B) Fotomicroscopia das cartilagens de crescimento de ratos com 40 dias, controle e hipertireoideos, demonstrando as alterações do gráfico (barra:18,5 $\mu \mathrm{m}$. CA: cartilagem articular; PE: placa epifisária). 

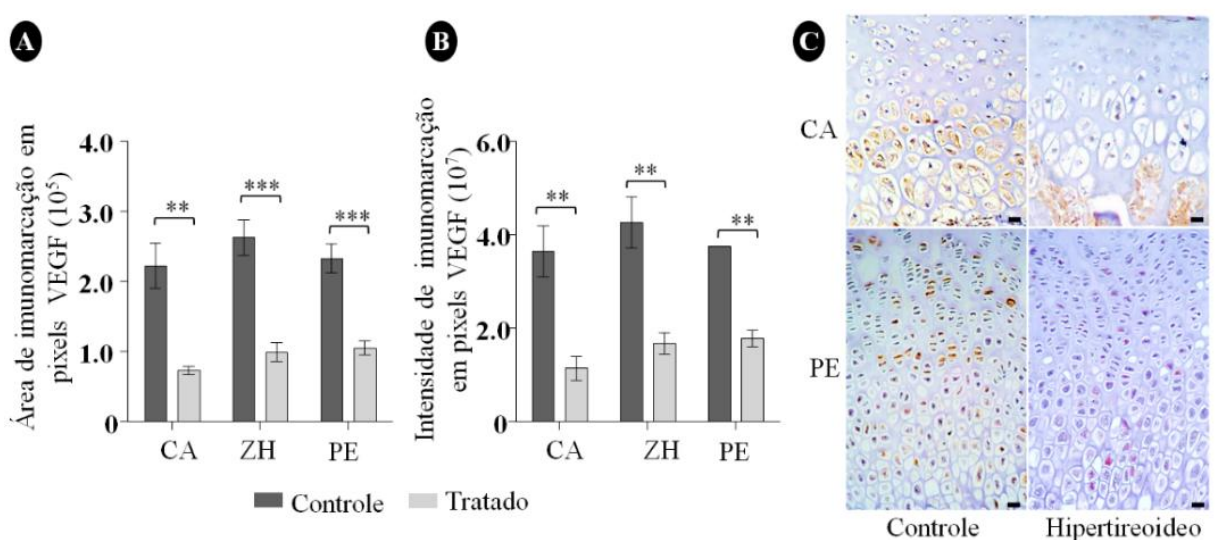

Figura 4. Expressão imuno-histoquímica de VEGF nas cartilagens de crescimento dos fêmures de ratos controle e hipertireoideos. A) Redução da área de expressão do VEGF na CA $(\mathrm{P}<0,01)$ e zona hipertrófica $(\mathrm{P}<0,01)$ e $\mathrm{PE}(\mathrm{P}<0,001)$ do grupo tratado em comparação ao controle. $\mathrm{B})$ Redução da intensidade de expressão do VEGF na cartilagem articular $(\mathrm{P}<0,01)$ na zona hipertrófica $(\mathrm{P}<0,01)$ e na placa epifisária $(\mathrm{P}<0,001)$ do grupo tratado em comparação ao controle. C) Fotomicroscopia das cartilagens de crescimento demonstrando as alterações evidenciadas nos gráficos (barra:18,5 $\mu \mathrm{m}$. CA: cartilagem articular; PE: placa epifisária; ZH: zona hipertrófica.

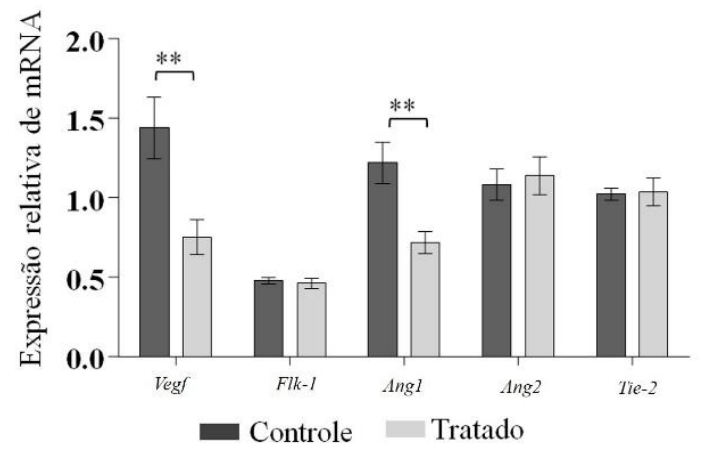

Figura 5. Expressão dos transcritos gênicos para Vegf, Flk-1, Ang1, Ang2 e Tie-2 pela técnica de RT-PCR em tempo real, nas cartilagens de crescimento da região distal dos fêmures de ratos controle e hipertireoideos.

\section{DISCUSSÃO}

A eficácia do tratamento com L-tiroxina foi atestada pela determinação da concentração plasmática elevada de $\mathrm{T}_{4}$ livre nas ratas aos 20 dias de lactação e de $T_{3}$ total e $T_{4}$ livre na prole tratada com 40 dias de idade. Adicionalmente, as avaliações morfológicas e morfométricas da tireoide da prole também endossaram as alterações plasmáticas. O aumento do diâmetro folicular associado à redução do epitélio da tireoide do grupo hipertireoideo constituem achados similares aos observados em pesquisas que induziram hipertireoidismo em ratos e camundongos adultos (Serakides et al., 2000; Ferreira et al., 2007) e são decorrentes do feedback negativo exercido pelo excesso de hormônios sobre a glândula (Fisher et al., 2000; Higuchi et al., 2005).

Estudos demonstraram que as disfunções tireoidianas afetam o crescimento e o desenvolvimento de diversos órgãos (Cooper, 2003). Todavia, não foi observada diferença no peso corporal entre os ratos hipertireoideos e controle. A associação entre baixo peso fetal, ao nascimento e na infância, em pacientes com tireotoxicose, tem sido relatada (Polak et al., 2006; Männistö et al., 2013), semelhantemente ao observado em adultos. Sugere-se que esse baixo peso seja devido ao aumento do catabolismo corporal causado pelo excesso de hormônios tireoidianos (Anselmo et al., 2004; Mestman, 1998). Apesar dessa associação, nem 
todos os indivíduos com hipertireoidismo apresentam redução do peso corporal (Männistö et al., 2013). Em alguns casos, as características clínicas da tireotoxicose são discretas e o estado hipertireoideo é evidenciado por meio de exames bioquímicos (Bursell e Warner, 2007).

Resultados preliminares demonstraram que a prole de ratas hipertireoideas, ao nascimento e ao desmame, apresenta redução do crescimento longitudinal do fêmur (Ribeiro, 2016). Ao contrário, neste estudo, a largura óssea se reduziu, sem alteração do crescimento longitudinal. Em camundongos machos adultos com hipertireoidismo, foi descrita redução na espessura da cortical femoral em decorrência da supremacia do processo de reabsorção frente à aposição óssea (Tsourdi et al., 2015). Embora não tenha sido escopo deste estudo avaliar a reabsorção óssea, pode-se sugerir que, no tecido ósseo trabecular, não houve supremacia de nenhum desses dois processos, uma vez que a quantidade de tecido ósseo trabecular foi semelhante entre grupos. No entanto, existe divergência com relação à altura de indivíduos com hipertireoidismo durante o crescimento. A taxa de crescimento pode ser variável, havendo aceleração do crescimento nos estágios iniciais, seguida por desaceleração e interrupção final do crescimento, fazendo com que alguns indivíduos apresentem estatura final menor (Bursell e Warner, 2007). Mas uma avaliação retrospectiva do padrão de crescimento em crianças com tireotoxicose diagnosticadas na fase pré-púbere ou no início da puberdade concluiu que a curva de crescimento dessas pacientes não difere do padrão de crescimento geral da população (Jaruratanasirikul e Sriplung, 2006).

Com base na avaliação histomorfométrica, não houve diferença entre grupos com relação à espessura da placa epifisária e das suas zonas, com exceção da zona proliferativa, que apresentou espessura menor em comparação ao controle. A cartilagem articular e suas zonas nos ratos hipertireoideos também apresentaram menor espessura quando comparados ao controle. A taxa de proliferação dos condrócitos avaliada pela imunoexpressão de CDC-47 foi menor nos animais hipertireoideos, em comparação ao controle. Esse resultado pode justificar, pelo menos em parte, o menor tamanho da zona proliferativa nos animais tratados, uma vez que fisiologicamente essa zona é a que apresenta maior proliferação celular na placa epifisária (Romereim et al., 2014).

A alteração na estrutura das zonas da placa epifisária evidenciada neste estudo também já foi descrita por outros pesquisadores (Stevens et al., 2000; Freitas et al., 2005; Desjardin et al., 2014), pois T3 é um regulador fundamental para a maturação da cartilagem e expansão clonal da zona de repouso e subsequente diferenciação (Rabier et al., 2006; Bassett et al., 2007). Os condrócitos apresentam comportamentos específicos para regular sua própria morfogênese, exemplificadas pela orientação do plano de divisão mitótica e pela formação da coluna de condrócitos na zona proliferativa. Essa sinalização ocorre via Wnt $\beta$-catenina, que é crucial para alinhar os planos de divisão e promover a formação das colunas dos condrócitos da zona de proliferação (Topczewski et al., 2001; Li e Dudley, 2009). Já foi descrito que os hormônios da tireoide ativam a via de sinalização Wnt $\beta$-catenina em cultivos de condrócitos da placa epifisária de ratos e regulam, em parte, a diferenciação terminal de condrócitos da placa epifisária (Wang et al., 2007). Dessa forma, as alterações na via de sinalização Wnt $\beta$-catenina pelos hormônios tireoidianos é uma das hipóteses para explicar a alteração na morfologia da placa epifisária observada nos animais submetidos ao excesso de tiroxina materna e pós-natal.

O excesso de tiroxina não induziu alterações no tecido ósseo trabecular dos ratos com 40 dias de idade. É fato que o hipertireoidismo pode aumentar a quantidade de tecido ósseo quando há supremacia da aposição em relação à reabsorção óssea. No entanto, as consequências dessa disfunção sobre o tecido ósseo são variáveis e dependentes de fatores, como dose de tiroxina administrada, perfil sérico dos hormônios sexuais, curso da doença (Serakides et al., 2004), sítio ósseo (Suwanwalaikorn et al., 1996; Milne et al., 1998) e idade (Nicholls et al., 2012). Assim, no hipertireoidismo, a massa óssea pode estar aumentada, normal ou reduzida (Mundy et al., 1976; Allain et al., 1995; Karga et al., 2004; Serakides et al., 2004; Desjardin et al., 2014). Similar aos achados deste estudo, Allain et al. (1995) também não encontraram alteração no volume de osso trabecular em ratos hipertireoideos com seis semanas de idade. 
O excesso de tiroxina reduziu a expressão proteica e gênica de VEGF nas cartilagens de crescimento dos ratos com 40 dias de idade. Alguns estudos têm demonstrado que o VEGF pode atuar como mediador essencial durante $o$ processo de formação e crescimento ósseos endocondrais, pois apresenta múltiplas funções não apenas na angiogênese do molde cartilaginoso, mas também em diferentes aspectos do crescimento ósseo (Zelzer e Olsen, 2005; Dai e Rabie, 2007; Berendsen e Olsen, 2014; Liu e Olsen, 2014). Ao contrário do observado na cartilagem, muitas pesquisas correlacionam o hipertireoidismo ao aumento na vascularização em tecidos, como a adrenal de fetos submetidos ao hipertireoidismo na gestação (Karaca et al., 2015), e em tecidos como corpo lúteo (Silva et al., 2013) e placenta (Silva et al., 2015). Durante o crescimento ósseo endocondral, a angiogênese mediada pelo VEGF é importante para a formação e a reabsorção da cartilagem, assim como para a mineralização (Carlevaro et al., 2000; Maes et al., 2002). A inativação do VEGF nas cartilagens de crescimento reduz quase que completamente a invasão dos vasos sanguíneos na cartilagem hipertrófica e compromete a formação de osso trabecular, com inibição do crescimento (Gerber et al., 1999).

Não foi observada alteração na expressão gênica de Flk-1, mesmo na presença de menor expressão de VEGF nas cartilagens de crescimento de ratos de 40 dias submetidos ao excesso de tiroxina. Sabe-se que o VEGF atua por meio da ligação com seus receptores de tirosina quinase, VEGFR-1 (Flt1) e VEGFR-2 (Flk-1/KDR) (Ferrara et al., 2003; Dai e Rabie, 2007), e a expressão desses receptores é autorregulada e estimulada pelo próprio VEGF (Andraweera et al., 2012). Foi constatado que, em linhagens de células pré-osteoblásticas, a inibição da ligação entre VEGF-A e $\mathrm{B}$ ao VEGFR-1 por tratamento com um bloqueador pode ser compensada pela ligação de VEGF-A, $\mathrm{C}$ e -D ao VEGFR-2, sugerindo o possível envolvimento desse outro receptor na regulação da diferenciação osteogênica (Deckers et al., 2000).

Associada à menor expressão gênica de VEGF, houve redução da expressão de Ang1 nos animais tratados. Apesar de o VEGF apresentar maior expressão durante o crescimento de osso humano, tanto a Ang1 quanto a Ang2 são coexpressas com o VEGF em locais de ossificação endocondral e de remodelamento ósseo. Na cartilagem, tanto as proteínas quanto a expressão de mRNA para Ang1 e Ang2 aumentam com a diferenciação dos condrócitos. No entanto, a Ang2 apresenta maior intensidade de expressão, principalmente nas zonas de proliferação e hipertrófica próximas de vasos sanguíneos (Horner et al., 2001). Durante a vida embrionária e fetal e durante o crescimento pósnatal, a angiogênese ocorre concomitantemente ao processo de proliferação celular. A vasculatura fornece oxigênio, nutrientes e fatores de crescimento às células e aos tecidos (Karaca et al., 2015). Para que isso ocorra, a matriz extracelular das cartilagens de crescimento desempenha função importante na difusão de substâncias, particularmente das moléculas de sinalização e dos fatores de crescimento (Cortes et al., 2009). Desta forma, é possível que a redução dos fatores pró-angiogênicos observados nas cartilagens de crescimento de ratos hipertireoideos possa impedir a difusão de moléculas pela matriz extracelular, alterando a composição da matriz cartilaginosa.

\section{CONCLUSÃO}

Conclui-se que o excesso de tiroxina materna associado ao hipertireoidismo pós-natal reduz a largura da diáfise femoral, a proliferação celular e a expressão imuno-histoquimica e/ou dos transcritos gênicos para VEGF e Ang1 nas cartilagens de crescimento de ratos.

\section{REFERÊNCIAS}

ALLAIN, T.J.; THOMAS, I.M.R.; McGREGOR, I.A.M.; SALISBURY, J.R. Histomorphometric study of bone changes in thyroid dysfunction in rats. Bone, v.16, p.505-509, 1995.

ANDRAWEERA, P.H.; DEKKER, G.A.; ROBERTS, C.T. The vascular endothelial growth factor family in adverse pregnancy outcomes. Hum. Reprod. Update., v.18, p.436457, 2012.

ANSELMO, J.; CAO, D.; KARRISON, T. et al. Fetal loss associated with excess thyroid hormone exposure. J. Am. Med. Assoc., v.292, p.691-695, 2004.

BALLOCK, R.T.; O’KEEFE, R.J. Physiology and pathophysiology of the growth plate. Birth Defects Res. C Embryo Today, v.69, p.123-143, 2003.

BASSETT, J.H.; NORDSTRÖM, K.; BOYDE, A. et al. Thyroid status during skeletal development determines adult bone structure and mineralization. Mol. Endocrinol., v.21, p.1893-1904, 2007. 
BERENDSEN, A.D.; OLSEN, B.R. How Vascular Endothelial Growth Factor-A (VEGF) regulates differentiation of mesenchymal stem cells. J. Histochem. Cytochem., v.62, p.103-108, 2014.

BURSELL, J.D.H.; WARNER, J.T. Interpretation of thyroid function in children. Paediatr. Child Health, v.17, p.361-365, 2007.

CARLEVARO, M.F.; CERMELLI, S.; CANCEDDA, R.; DESCALZI CANCEDDA, F. Vascular endothelial growth factor (VEGF) in cartilage neovascularization and chondrocyte differentiation: auto-paracrine role during endochondral bone formation. J. Cell. Sci., v.113, p.59-69, 2000.

CARRINGTON, J.L.; REDDI, A.H. Parallels between development of embryonic and matrix-induced endochondral bone. Bioessays, v.13, p.403-408, 1991.

COOPER, D.S. Hyperthyroidism. Lancet, v.362, p.459-468, 2003.

CORTES, M.; BARIA, A.T.; SCHWARTZ, N.B. Sulfation of chondroitin sulfate proteoglycans is necessary for proper Indian hedgehog signaling in the developing growth plate. Development, v.136, p.1697-1706, 2009.

DAI, J.; RABIE, A.B. VEGF: an essential mediator of both angiogenesis and endochondral ossification. J. Dent. Res., v.86, p.937-950, 2007.

DECKERS, M.M.; KARPERIEN, M.; VAN DER BENT, C. et al. Expression of vascular endothelial growth factors and their receptors during osteoblast differentiation. Endocrinology, v.141, p.1667-1674, 2000.

DESJARDIN, C.; CHARLES, C.; BENOIST-LASSELIN, C. et al. Chondrocytes play a major role in the stimulation of bone growth by thyroid hormone. Endocrinology, v.155, p.3123-3135, 2014

FERRARA, N.; GERBER, H.P.; LECOUTER, J. The biology of VEGF and its receptors. Nat. Med., v.9, p.669676, 2003.

FERREIRA, E.; SILVA, A.E.; SERAKIDES, R. et al. Model of induction of thyroid dysfunctions in adult female mice. Arq. Bras. Med. Vet. Zootec., v.59, p.1245-1249, 2007.

FISHER, D.A.; SCHOEN, E.J.; LA FRANCHI, S. et al. The hypothalamic-pituitary-thyroid negative feedback control axis in children with treated congenital hypothyroidism. $J$. Clin. Endocrinol. Metab., v.85, p.2722-2727, 2000.

FREITAS, F.R.S.; CAPELO, L.P.; SHEA, P.J.O. et al. The thyroid hormone receptor $\beta$-Specific Agonist GC-1 selectively affects the bone development of hypothyroid rats. J. Bone Miner. Res., v.20, p.294-304, 2005

GERBER, H.P.; VU, T.H.; RYAN, A.N. et al. VEGF couples hypertrophic cartilage remodeling, ossification and angiogenesis during endochondral bone formation. Nat. Med., v.5, p.33-42, 1999.

HIGUCHI, R.; MIYAWAKI, M.; KUMAGAI, T. et al. Central hypothyroidism in infants who were born to mothers with thyrotoxicosis before 32 weeks gestation: 3 cases. Pediatrics, v.115, p.623-625, 2005.
HORNER, A.; BORD, S.; KELSALL, A.W. et al. Tie2 ligands angiopoietin-1 and angiopoietin-2 are coexpressed with vascular endothelial cell growth factor in growing human bone. Bone, v.28, p.65-71, 2001.

HUNZIKER, E.B. Mechanism of longitudinal bone growth and its regulation by growth plate chondrocytes. Microsc. Res. Tech., v.28, p.505-519, 1994.

JARURATANASIRIKUL, S.; SRIPLUNG, H. Growth pattern of childhood thyrotoxicosis: Longitudinal follow-up to final height. J. Med. Assoc. Thail., v.89, p.1396-1399, 2006.

KARACA, T.; HULYA, U.Z.Y.; KARABACAK, R. et al. Effects of hyperthyroidism on expression of vascular endothelial growth factor (VEGF) and apoptosis in fetal adrenal glands. Eur. J. Histochem., v.59, p.258-262, 2015.

KARGA, H.; PAPAPETROU, P.D.; KORAKOVOUNI, A. et al. Bone mineral density in hyperthyroidism. Clin. Endocrinol., v.61, p.466-472, 2004.

LI, Y.; DUDLEY, A.T. Noncanonical frizzled signaling regulates cell polarity of growth plate chondrocytes. Development, v.136, p.1083-1092, 2009.

LIU, Y.; OLSEN, B.R. Distinct VEGF functions during bone development and homeostasis. Arch. Immunol. Ther. Exp., v.62, p.363-368, 2014.

MAES, C. Role and regulation of vascularization processes in endochondral bones. Calcif Tissue Int., v.92, p.307-323, 2013.

MAES, C.; CARMELIET, P.; MOERMANS, K. et al. Impaired angiogenesis and endochondral bone formation in mice lacking the vascular endothelial growth factor isoforms VEGF164 and VEGF188. Mech. Dev., v.111, p.61-73, 2002.

MÄNNISTÖ, T.; MENDOLA, P.; REDDY, U.; LAUGHON, S.K. Neonatal outcomes and birth weight in pregnancies complicated by maternal thyroid disease. Am. J. Epidemiol., v.178, p.731-740, 2013.

MEDICI, M.; TIMMERMANS, S.; VISSER, W. et al. Maternal thyroid hormone parameters during early pregnancy and birth weight: the generation r study. J. Clin. Endocrinol. Metab., v.98, p.59-66, 2013.

MESTMAN, J.H. Hyperthyroidism in pregnancy. Best Pract. Res. Clin. Endocrinol. Metab., v.18, p.267-288, 2004.

MESTMAN, J.H. Hyperthyroidism in pregnancy. Endocrinol. Metab. Clin. N. Am., v.27, p.127-149, 1998.

MILNE, M.; KANG, M.; QUAIL, J.M.; BARAN, D.T. Thyroid hormone excess increases insulin-like growth factor I transcripts in bone marrow cell cultures: divergent effects on vertebral and femoral cell cultures. Endocrinology, v.139, p.2527-2534, 1998

MUNDY, G.R.; SHAPIRO, J.L.; BANDELIN, J.G. et al. Direct stimulation of bone resorption by thyroid hormones. $J$. Clin. Invest., v.58, p.529-534, 1976.

NICHOLLS, J.J.; BRASSILL, M.J.; WILLIAMS, G.R.; BASSETT, J.H. The skeletal consequences of thyrotoxicosis. J. Endocrinol., v.213, p.209-221, 2012. 
PITOL， D.L.; CAETANO, F.H.; LUNARDI, L.O Microwave-induced fast decalcification of rat bone for electron microscopic analysis: an ultrastructural and cytochemical study. Braz. Dent. J., v.18, p.153-157, 2007.

POLAK, M.; LEGAC, I.; VUILLARD, E. et al. Congenital hyperthyroidism: the fetus as a patient. Horm. Res., v.65, p.235-242, 2006

RABIER, B.; WILLIAMS, A.J.; MALLEIN-GERIN, F. et al. Thyroid hormone-stimulated differentiation of primary rib chondrocytes in vitro requires thyroid hormone receptor beta. J. Endocrinol., v.191, p.221-228, 2006.

RIBEIRO, L.G.R. Efeito do excesso de tiroxina materna e pós-natal sobre o perfil proliferativo, angiogênico e de sintese das cartilagens de crescimento de ratos. 2016. 157f Tese (Doutorado em Ciência Animal/Patologia Animal) Escola de Veterinária, Universidade Federal de Minas Gerais, Belo Horizonte, MG.

ROMEREIM, S.M.; CONOAN, N.H.; CHEN, B.; DUDLEY, A.T. et al. A dynamic cell adhesion surface regulates tissue architecture in growth plate cartilage. Development, v.141, p.2085-2095, 2014

SAMPAIO, I. Estatística aplicada à experimentação animal. Belo Horizonte: FEP/MVZ, 2002. 256p.

SEGNI, M.; GORMAN, C.A. The aftermath of childhood hyperthyroidism. J. Pediatr. Endocrinol. Metab., v.14, p.1277-1282, 2001

SEGNI, M.; LEONARDI E.; MAZZONCINI, B. et al. Special features of graves' disease in early childhood. Thyroid, v.9, p.871-877, 1999.

SERAKIDES, R.; NUNES, V.A.; NASCIMENTO, E.F. et al Hypogonadism and thyroid function in hyper and euthyroid rats. Arq. Bras. Med. Vet. Zootec., v.52, p.571-578, 2000.

SERAKIDES, R.; NUNES, V.A.; OCARINO, N.M. et al. Efeito da associação hipertireoidismo-castração no osso de ratas adultas. Arq. Bras. Endocrinol. Metab., v.48, p.875-884, 2004
SERAKIDES, R.; OCARINO, N.M.; MAGALHÃES, F.C. et al. Histomorfometria óssea de ratas hipertireoideas lactantes e não-lactantes. Arq. Bras. Endocrinol. Metab., v.52, p.677683, 2008.

SILVA, J.F.; OCARINO, N.M.; SERAKIDES, R. Placental angiogenic and hormonal factors are affected by thyroid hormones in rats. Pathol. Res. Pract., v.211, p.226-234, 2015

SILVA, J.F.; OCARINO, N.M.; VIEIRA, A.L.S. et al. Effects of hypo- and hyperthyroidism on proliferation, angiogenesis, apoptosis and expression of COX-2 in the corpus luteum of female rats. Reprod. Domest. Anim., v.48, p.691-698, 2013.

STEVENS, D.A.; HASSERJIAN, R.P.; ROBSON, H. et al. Thyroid hormones regulate hypertrophic chondrocyte differentiation and expression of parathyroid hormone-related peptide and its receptores during endochondral bone formation. J. Bone Miner. Res., v.15, p.2431-2442, 2000

SUWANWALAIKORN, S.; ONGPHIPHADHANAKUL B.; BRAVERMAN, L.E.; BARAN, D.T. Differential responses of femoral and vertebral bones to long-term excessive L-thyroxine administration in adult rats. Eur. J. Endocrinol., v.134, p.655-659, 1996.

TOPCZEWSKI, J.; SEPICH, D.S.; MYERS, D.C. et al. The zebrafish glypican knypek controls cell polarity during gastrulation movements of convergent extension. Dev. Cell., v.1, p.251-264, 2001

TSOURDI, E.; RIJNTJES, E.; KÖHRLE, J. Hyperthyroidism and hypothyroidism in male mice and their effects on bone mass, bone turnover, and the wnt inhibitors sclerostin and dickkopf-1. Endocrinology, v.156, p.3517-3527, 2015.

WANG, L.; SHAO, Y.Y.; BALLOCK, R.T. Thyroid hormone interacts with the Wnt/beta-catenin signaling pathway in the terminal differentiation of growth plate chondrocytes. J. Bone Miner. Res., v.22, p.1988-1995, 2007.

ZELZER, E.; OLSEN, B.R. Multiple roles of vascular endothelial growth factor (VEGF) in skeletal development, growth, and repair. Curr. Top. Dev. Biol., v.65, p.169-87, 2005 